\title{
Long-Term Biostability of Pet Vascular Prostheses
}

\author{
Florence Dieval, ${ }^{1}$ Foued Khoffi, ${ }^{1}$ Riaz Mir, ${ }^{1}$ Walid Chaouch, ${ }^{2}$ Didier Le Nouen, ${ }^{3}$ \\ Nabil Chakfe, ${ }^{4}$ and Bernard Durand ${ }^{1}$ \\ ${ }^{1}$ Laboratoire de Physique et Mécanique Textiles, ENSISA, 11 rue des Frères Lumières, 68093 Mulhouse Cedex, France \\ ${ }^{2}$ Textile Research Unit, High Technology Institute, Hadj Ali Soua, Ksar-Hellal 5070, Tunisia \\ ${ }^{3}$ Laboratoire de Chimie Organique et Bio-organique, École Nationale Supérieure de Chimie de Mulhouse, Université de Haute Alsace, \\ 68093 Mulhouse, France \\ ${ }^{4}$ Department of Vascular Surgery, Les Hôpitaux Universitaires de Strasbourg, University of Strasbourg, 67000 Strasbourg, France
}

Correspondence should be addressed to Florence Dieval, florence.dieval@uha.fr

Received 22 July 2011; Revised 8 November 2011; Accepted 16 November 2011

Academic Editor: Haojun Liang

Copyright (C) 2012 Florence Dieval et al. This is an open access article distributed under the Creative Commons Attribution License, which permits unrestricted use, distribution, and reproduction in any medium, provided the original work is properly cited.

\begin{abstract}
PET Vascular prostheses are susceptible to physical modification and chemical degradation leading sometimes to global deterioration and rupture of the product. To understand the mechanisms of degradation, we studied 6 vascular prostheses that were explanted due to medical complications. We characterized their level of degradation by comparing them with a virgin prosthesis and carried out physicochemical and mechanical analyses. Results showed an important reduction of the fabric's mechanical properties in specific areas. Moreover, PET taken from these areas exhibited structural anomalies and was highly degraded even in virgin prostheses. These results suggest that vascular prostheses have weak areas prior to implantation and that these areas are much more prone to in vivo degradation by human metabolism. Manufacturing process could be responsible for these weaknesses as well as designing of the compound. Therefore, we suggest that a more controlled manufacturing process could lead to a vascular prosthesis with enhanced lifespan.
\end{abstract}

\section{Introduction}

Arteries are blood vessels that carry oxygen and nutrients from the heart to the rest of the body. Healthy arteries are flexible, strong, and elastic. With age, vascular diseases can occur leading to a lumen with restricted section or to a loss of elastic properties of arteries (Figures 1(a) and 1(b)).

Vascular diseases are often treated by replacing the dysfunctional blood vessel with a vascular prosthesis. Fabric materials were first used as vascular prostheses in the 1950s, when Voorhees et al. [1] implanted a polymeric vascular graft manufactured from vinyl chloride and acrylonitrile. Since then, a number of polymers have been used to fabricate vascular prostheses. Ideally, the prostheses should have the same properties as the healthy arteries to avoid weakening of the heart. Polyethylene terephthalate (PET) remains a primary choice for vascular prostheses because of its biostability and biocompatibility. In spite of this success, the lifespan of PET vascular prostheses is limited and many complications can occur following a relatively long in vivo stay (Figures 1(c)1(e)). Failures may be related to the deteriorations that occur during manufacturing steps, implanting steps, and the time of stay in the body [2-10].

Dilatation and rupture (Figure 1(e)) are two complications of long-term degradation of polyester vascular prostheses [11-13]. The mechanisms of degradation are not yet clearly understood but are probably multifactorial. Degradation may be related to a preexisting weakness of the prosthesis prior to implantation, such as a poor design of the textile structure or alterations of the prosthesis during its manufacturing process $[14,15]$. Currently, warp-knit structures have demonstrated a good long-term stability and are widely implanted. However, despite this good stability, sporadic ruptures were reported by researchers. In most cases, these ruptures consisted in general degeneration of the textile with huge degradation of the fibers and complete destruction of the prosthesis or more rarely in longitudinal ruptures [16-23]. In a previous study, we analyzed 20 


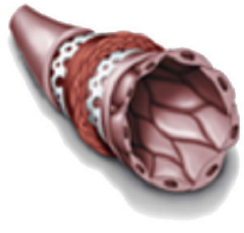

Artery

(a)

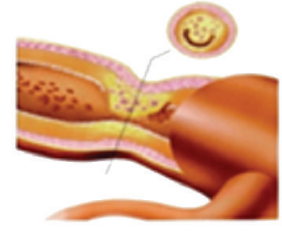

Artery disease

(b)

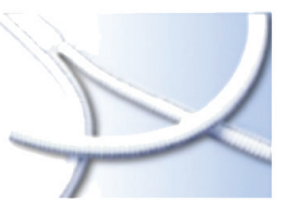

Prosthesis

(c)

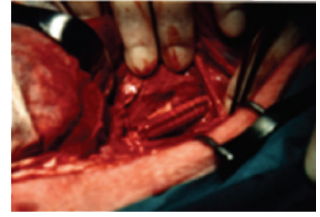

Prosthesis implanted

(d)
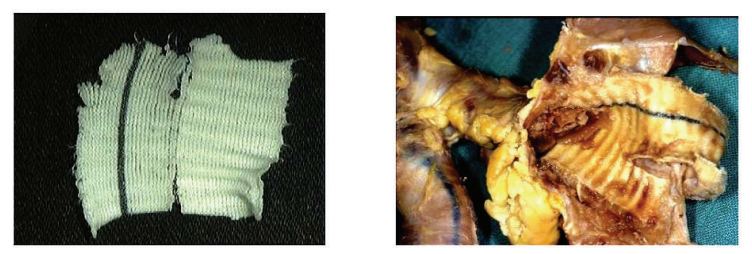

Rupture

Explants

(e)

FIGURE 1: Dysfunctions of arteries and prostheses. Sources: (b) http://archimede.bibl.ulaval.ca/archimede/fichiers/22413/ch02.html. (c) Pérouse medical.

explanted prostheses in which a longitudinal rupture had occurred [3]. One result of the study was that the ruptures occurred on two specific areas of the textile structure: the remeshing line and the guide line (Figure 2). Conclusion was that these areas were weak spots needing particular attention. We then performed chemical and mechanical investigations of virgin prostheses and demonstrated that these longitudinal ruptures observed on both remeshing and guide lines were predictable [24]. These areas of weakness seemed to be related to the manufacturing process which may induce physical and chemical modifications of the polyester yarns. These alterations may be considered as a premature ageing of the polyester before its implantation. Therefore, it is important to understand in detail what happens throughout the different steps of manufacturing (knitting, cleaning, compaction, crimping, and thermosetting) in order to improve the quality of the in vivo behavior of arterial prostheses and to avoid ruptures in the future. Previous studies have investigated the nature of morphological changes induced by ageing on PET fibers extracted from explanted prostheses [5-7]. Although these results found in the literature are very interesting, the other modifications such as chemical ageing that depends directly on the stay in the biological environment have not been assessed [2-7]. Therefore, these previous studies are considered insufficient and unable to give a total description of ageing. To know the type of modification that could arise in the polymer, complete physicochemical studies of explants have to be undertaken.

The goal of the present study was to investigate the physical and chemical degradation of polyethylene terephthalate yarns and filaments taken from specimens of our previous series of 6 explanted grafts in order to confirm in vitro data and to understand this ageing mechanism.

\section{Material and Methods}

2.1. The Prostheses. The explanted prostheses were Cooley Double Velour (CDV) and the Microvel Double Velour (MDV) (virgin and explanted prostheses (Figure 3)), both grafts being constructed by Meadox Medical, (Oakland, NJ, USA). Explanted specimens were collected from 1993 to 1998 through the collaboration of several hospitals in Europe. We have the largest stock of various prosthetic explants in Europe. Unfortunately, some explants collected are unexploitable due to their in vivo degradation, the quantity of the obtained explants was not sufficient.

For these prostheses, three different areas are distinguished (Figures 3 and 4 ). The first one corresponds to the columns made of black yarns, used by the surgeon to correctly place prostheses. These columns are named Guide Lines (GL). The second one corresponds to Remeshing Lines (RL) made of yarns that join the two parts of the basic knitting. The rest of the prosthesis forms the Standard Knit (SK). For guide lines and standard knit, there are two types of yarns: flat (FFP: made with short filaments) and textured (FFT: made with long filaments) yarns. We analyzed explants where enough quantity of material was available to complete our protocol ( 6 of the 20 explants). Their mean duration of implantation was 202 months (range 156 to 240). The main characteristics of the prostheses are summarized in Table 1. Briefly, the processing was as follows: at the time of their reception in our laboratory, the prostheses were photographed and macroscopically analyzed with an optical microscope. The prostheses were then cleaned using a nondeleterious-specific treatment for PET fibers to undertake chemical investigations. For this treatment, the explants were immersed in a $10 \%$ sodium hypochlorite solution with soft agitation for 3 hours. They were then rinsed with distilled water, and hypochlorite remnants were neutralized 


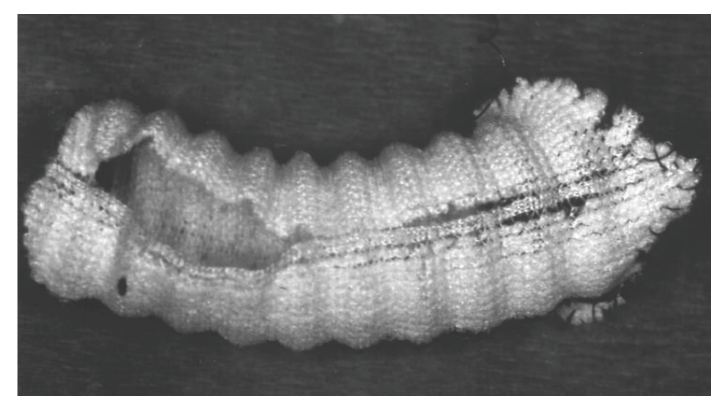

(a)

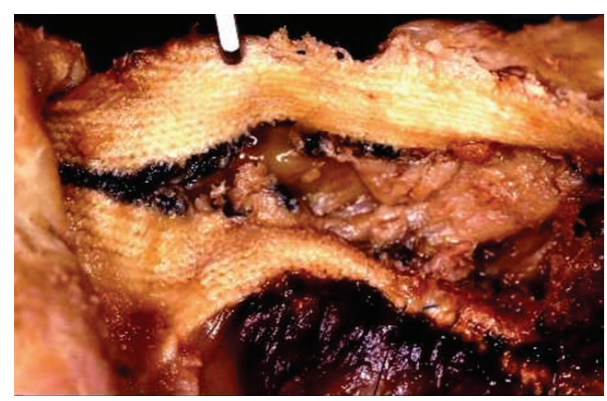

(b)

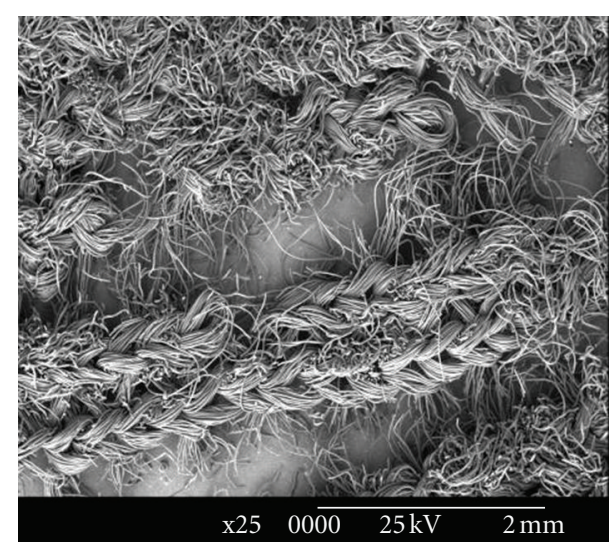

(c)

Figure 2: Macroscopic examination of Cooley Double Velour prosthesis: (a) ruptures on remeshing line. (b) rupture on guide line. (c) scanning electron microscopy examination of Cooley Double Velour prosthesis presenting a rupture on remeshing line.

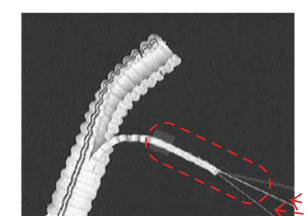

Virgin prosthesis

(a)

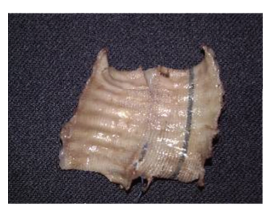

Explant

(b)

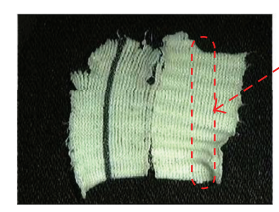

Explant cleaning

(c)

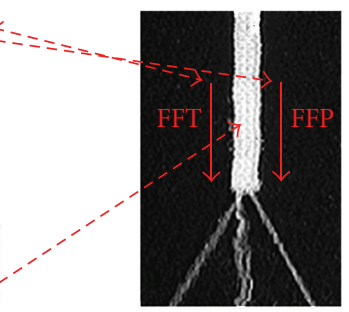

Textured yarn of standard knit (FFT) and flat yarn of standard knit (FFP)

(d)

FIGURE 3: Sample preparation.

with a $0.5 \%$ hydrogen peroxide solution. The prostheses were rinsed again with distilled water, dried, and stored.

Virgin prosthesis was used as a reference. So, in order to study only the effect of the chemical aging on the PET properties, this virgin prosthesis was sterilized and then it was cleaned with the same treatment as for the explants.
In this study, flat and texturized filaments of standard knit (FFP and FFT, resp. Figure 3(e)) were analyzed. The filaments were taken by unroving the prostheses.

2.2. Scanning Electron Microscopy. Scanning electron microscopy (Hitachi S-2360N; Elexience, Verrières le Buisson, 


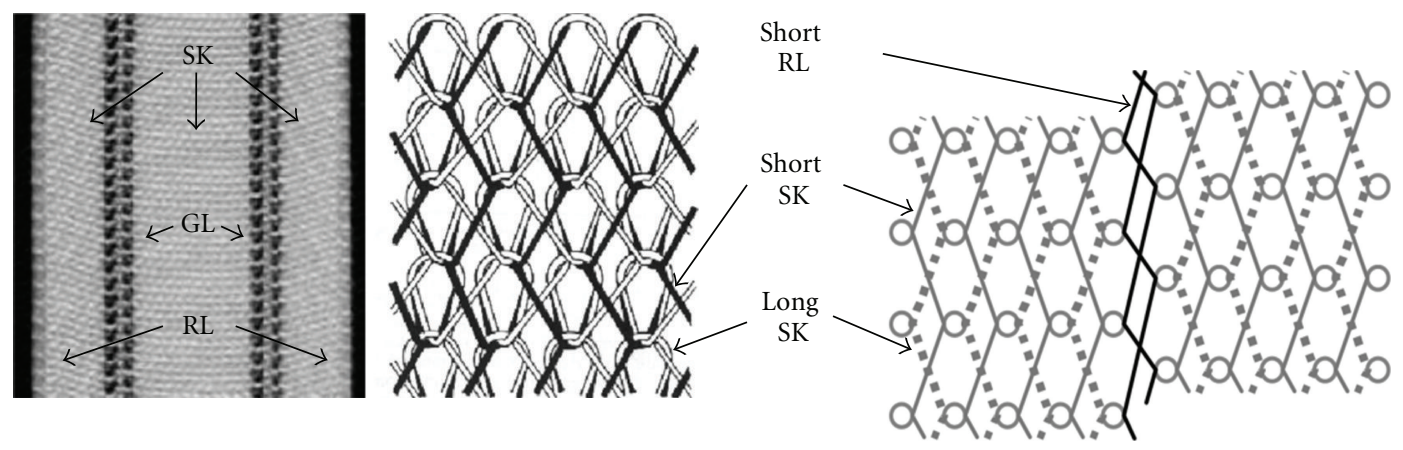

FIGURE 4: Schematic characterization of the textile structure of the virgin Cooley Double Velour prosthesis and of the virgin Microvel Double Velours prosthesis; (RL: remeshing line; SK: standard Knit, GL:Guide Line).

TABLE 1: Main characteristics of the explanted grafts. Reference number is the reference number given in the first clinical description of the series. (MDV: Microvel Double Velour; CDV: Cooley Double Velour; RL: remeshing line; GL: guide line).

\begin{tabular}{|c|c|c|c|c|c|c|c|c|}
\hline $\begin{array}{l}\text { Explant } \\
\text { reference }\end{array}$ & $\begin{array}{l}\text { Prosthetic } \\
\text { type }\end{array}$ & $\begin{array}{c}\text { Year of } \\
\text { implantation }\end{array}$ & $\begin{array}{c}\text { Year of } \\
\text { explantation }\end{array}$ & $\begin{array}{l}\text { Lifetime } \\
\text { (months) }\end{array}$ & $\begin{array}{l}\text { Reason for } \\
\text { explantation }\end{array}$ & $\begin{array}{l}\text { Location of } \\
\text { implantation }\end{array}$ & $\begin{array}{c}\text { Prosthetic } \\
\text { segment } \\
\text { affected }\end{array}$ & $\begin{array}{l}\text { Ruptured } \\
\text { area }\end{array}$ \\
\hline A & $\mathrm{CDV}$ & 1980 & 1993 & 156 & $\begin{array}{c}\text { Bilateral } \\
\text { false-aneurysm }\end{array}$ & $\begin{array}{c}\text { Axillo } \\
\text { bi-femoral }\end{array}$ & $\operatorname{limb}$ & $\mathrm{RL}$ \\
\hline B & $\mathrm{CDV}$ & 1981 & 1995 & 168 & $\begin{array}{l}\text { Multiple } \\
\text { false-aneurysms }\end{array}$ & $\begin{array}{c}\text { Axillo } \\
\text { bi-femoral }\end{array}$ & $\begin{array}{c}\text { Entire } \\
\text { prosthesis }\end{array}$ & RL, GL \\
\hline $\mathrm{C}$ & $\mathrm{CDV}$ & 1982 & 1999 & 204 & $\begin{array}{l}\text { False-aneurysm } \\
\text { and dilatation }\end{array}$ & $\begin{array}{c}\text { Aorto } \\
\text { bi-femoral }\end{array}$ & $\operatorname{limb}$ & GL \\
\hline $\mathrm{D}$ & $\mathrm{CDV}$ & 1979 & 1997 & 204 & False-aneurysm & $\begin{array}{c}\text { Axillo } \\
\text { bi-femoral }\end{array}$ & $\operatorname{limb}$ & $\mathrm{RL}, \mathrm{GL}$ \\
\hline $\mathrm{E}$ & $\mathrm{CDV}$ & 1978 & 1998 & 240 & False-aneurysm & $\begin{array}{c}\text { Aorto } \\
\text { bi-femoral }\end{array}$ & body & $\mathrm{RL}$ \\
\hline $\mathrm{F}$ & MDV & 1978 & 1998 & 240 & False-aneurysm & $\begin{array}{c}\text { Aorto } \\
\text { bi-femoral }\end{array}$ & $\operatorname{limb}$ & GL \\
\hline
\end{tabular}

France) was used to determine the deteriorations of the textile structure. The specimens were studied without metallization, in partial vacuum conditions $(0.1-0.15$ torr $)$, and under an accelerating voltage ranging from 8 to $18 \mathrm{KeV}$. These conditions ensured that the specimens were not altered for further investigations, and that a maximum rate of magnification of 200 was achieved. We studied the aspect of the ruptures and the filaments inside the yarns.

2.3. Filament Dynamometry. Filaments taken from yarns of the standard knit were studied by filament dynamometry using a dynamometer (Lhomargy, Ivry-sur-Seine, France). Ten samples were tested for each type of filament. The distance between the dynamometer jaws was $10 \mathrm{~mm}$ (with a pretension) as proposed by the recommendations of the national and international textile standards NF EN ISO 5079. The curves obtained for each specimen were recorded. The results were expressed as the tenacity in $\mathrm{cN} /$ tex with the average value and the coefficient of variation.

2.4. Density Gradient Column (DGC). The principle of this technique consists in immerging pieces of PET filaments $(\sim 1 \mathrm{mg})$ in a calibrated density gradient column obtained

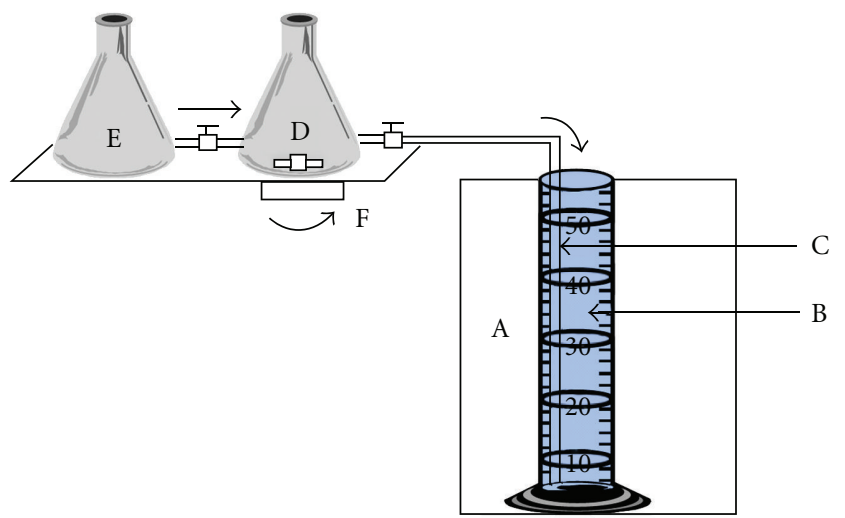

FIGURE 5: Experimental representation of the gradient density column. A: temperature controlled chamber; B: column of gradient density; C: capillary tubing; D: carbon tetrachloride solution; E: petroleum ether solution; F: magnetic agitator.

by mixing two miscible liquids at $23^{\circ} \mathrm{C}$ : carbon tetrachloride and petroleum ether (Figure 5). Thirty measures were performed for each sample. This technique allows the measurement of the density of the polymer in $\mathrm{g} / \mathrm{cm}^{3}$. 


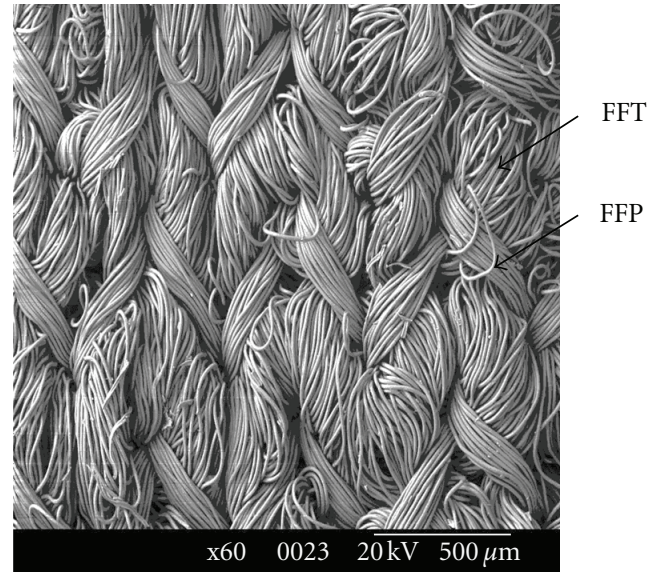

(a)

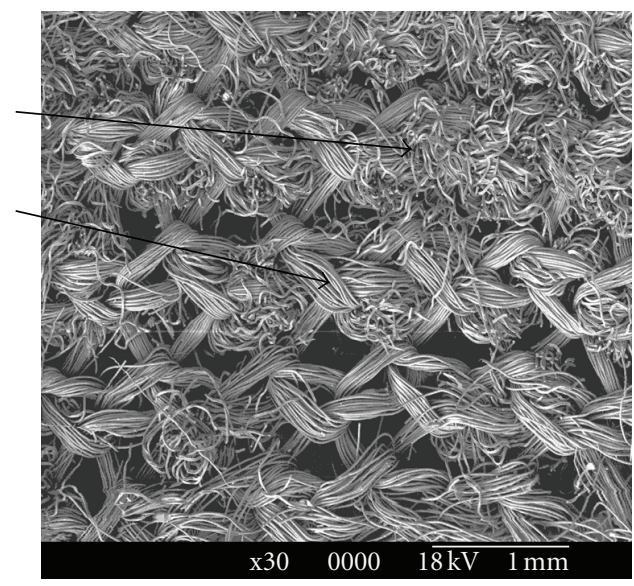

(b)

Figure 6: Scanning electron microscopy examination of Cooley Double Velours prosthesis: (a) virgin prosthesis, (b) explanted prosthesis, destruction of texturized yarn.

From this value, we can calculate the polymer's crystallinity percentage with the following equation [25]:

$$
\chi=\frac{\rho-\rho_{a}}{\rho_{c}-\rho_{a}} \times \frac{\rho_{a}}{\rho},
$$

where $\rho$ is the density of the polymer measured in the gradient density column, $\rho_{a}$ the density of the amorphous phase of PET, and $\rho_{c}$ the density of the crystalline phase of PET. These 2 values have been previously calculated for PET $\left(\rho_{a} 1,335 \mathrm{~g} \cdot \mathrm{cm}^{-3}\right.$ and $\left.\rho_{c} 1,445 \mathrm{~g} \cdot \mathrm{cm}^{-3}\right)$.

2.5. Infrared Microspectroscopy (IMS). We used a Brucker Fourier transform infrared (FTIR) spectrophotometer (Brucker Optics, Marne la Vallée, France) equipped with Brucker Optic software. The IMS in a transmission spectrum of PET fibers was recorded directly in the range of 2000$4000 \mathrm{~cm}^{-1}$. Each spectrum was made from an average of 200 scans at a resolution of $2 \mathrm{~cm}^{-1}$. The diaphragm opening was 0.9 , corresponding to an object diameter of $63 \mu \mathrm{m}$, and the microscope magnification was $15 x$. Each sample was dried overnight in a vacuum oven at $50^{\circ} \mathrm{C}$ before its study. We analysed 30 fibres (length: $6 \mathrm{~cm}$ ) (30 spectra) extracted from various zones of each prosthesis.

2.6. Nuclear Magnetic Resonance $\left(N M R^{H}\right)$. This technique was chosen to characterize the evolution of the macromolecular mass and to detect the presence of structural abnormalities of the polymer. NMR experiments were recorded at $400 \mathrm{MHz}$ on a Brucker Acance Spectrometer (Brucker Optics, Marne la Vallée, France) equipped with a QNP Zgradient probe. All the $1 \mathrm{H}$ NMR spectra were acquired with a $30^{\circ}$ pulse corresponding to a pulse width of $3.1 \mu \mathrm{s}$. The delay time between each pulse was $8 \mathrm{~s} .{ }^{1} \mathrm{H}$ NMR spectra were recorded during 4000 scans (number of acquired transients) for adequate ratio of signal to noise. The total acquisition time was approximately 14 hours.

Solutions were prepared by dissolving the PET samples in tetrachloroethane- $\mathrm{d} 2$ (Deuterated tetrachloroethane 99.9\% atom D) at $140^{\circ} \mathrm{C}$ (typically $2-4 \mathrm{mg}$ ) directly in an NMR tube and waiting for about 90 seconds to ensure a complete dissolution of the polymer, then the mixture was cooled to ambient temperature. The experiments were run at room temperature. For these analyses, Topspin 1.3 software was used to treat the spectra and ${ }^{1} \mathrm{D}$ NMR processor 11.0 (ACD Labs, Toronto, Canada) software was used to determine the peak integrals. Prior to signal integration, a linear baseline correction was applied between 2 and $12 \mathrm{ppm}$. We respected the same construction of the baseline for all spectra; so the choice of the baseline did not influence the obtained ${ }^{1} \mathrm{H}$ NMR results.

\section{Results}

3.1. Scanning Electron Microscopy. The specimens were examined under scanning electron microscopy on the external and internal surfaces. We found major deteriorations in the texturized filaments from the standard knit and that constitute the velour (Figure 6). In most of the samples, they were completely broken with transverse fractures (Figure 7). This phenomenon was mainly observed on the external surface of the prostheses, where the velour had sometimes completely disappeared. SEM micrographs of the virgin prosthesis showed that the remeshing line appeared as two columns of stitches that were very close (Figure 2(c)). When considering SEM micrographs of ruptured remeshing lines, we found that the texturized filaments of the velour were all ruptured with a complete destruction of the velour. The ruptures occurred in all samples on the flat filaments of the yarns between the two columns of the remeshing line and the first column of the standard knit. The breaks in the flat filaments were perpendicular to their axes. The guide line showed the same aspect of knitting under scanning electron microscopy. The examination of the areas of rupture demonstrated a complete rupture of all of the texturized filaments of the velour. The flat filaments were transversely broken with an aspect of incomplete and gradual rupture 
TABle 2: Results of the filament dynamometry performed on short and long filaments of the specimens. Prosthesis number is the reference number given in the first clinical description of the series. (CDV: Cooley Double Velour; MDV: Microvel Double Velour; CV: coefficient of variation).

\begin{tabular}{|c|c|c|c|c|c|}
\hline \multirow{2}{*}{ Prostheses } & & \multicolumn{2}{|c|}{ Tenacity (cN/tex) } & \multicolumn{2}{|c|}{ Elongation at rupture (\%) } \\
\hline & & Average & $\mathrm{CV}(\%)$ & Average & CV $(\%)$ \\
\hline \multirow{2}{*}{ Virgin CDV } & FFP (short) & 28.0 & 6.7 & 63.5 & 11.8 \\
\hline & FFT (Long) & 26.4 & 11.8 & 74.4 & 14.8 \\
\hline \multirow{2}{*}{ A } & FFP (short) & 26.9 & 32.7 & 25.8 & 42.2 \\
\hline & FFT (Long) & 24.7 & 33.9 & 27.8 & 48.1 \\
\hline \multirow{2}{*}{ B } & FFP (short) & 27.9 & 29.8 & 31.6 & 38.2 \\
\hline & FFT (Long) & 23.8 & 40.1 & 35.5 & 37.3 \\
\hline \multirow{2}{*}{$\mathrm{C}$} & FFP (short) & 12.6 & 48.2 & 7.33 & 113.1 \\
\hline & FFT (Long) & 12.2 & 46.8 & 20.8 & 84.7 \\
\hline \multirow{2}{*}{$\mathrm{D}$} & FFP (short) & 27.6 & 31.1 & 24.6 & 38.0 \\
\hline & FFT (Long) & 25.9 & 40.1 & 28.9 & 45.8 \\
\hline \multirow{2}{*}{$\mathrm{E}$} & FFP (short) & 24.8 & 21.2 & 29.3 & 26.1 \\
\hline & FFT (Long) & 23.6 & 29.4 & 35.6 & 41.3 \\
\hline \multirow{2}{*}{ Virgin MDV } & FFP (short) & 25.4 & 3.6 & 67.9 & 11.3 \\
\hline & FFT (Long) & 22.8 & 14.4 & 62.7 & 19.1 \\
\hline \multirow{2}{*}{ F } & FFP (short) & 24.6 & 46.5 & 22.6 & 52.0 \\
\hline & FFT (Long) & 21.7 & 48.3 & 23.8 & 55.9 \\
\hline
\end{tabular}

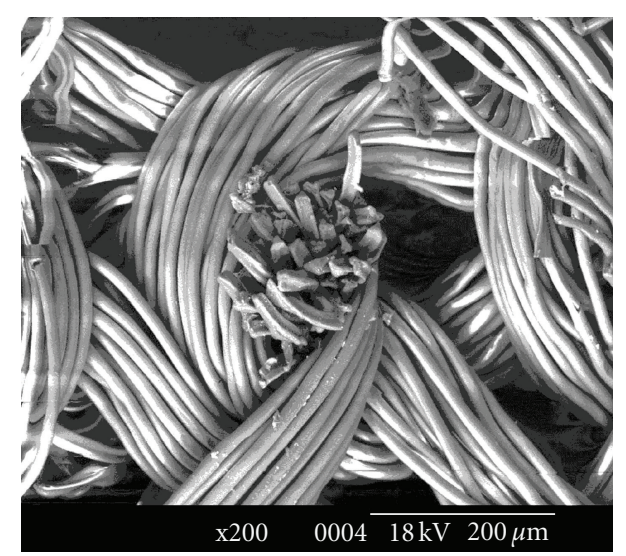

FIgURE 7: Scanning electron microscopy examination of Cooley Double Velours prosthesis. Transversal breaks of trilobar filament.

at the edges of the ruptures. At least in the absence of macroscopic rupture on remeshing or guide lines, alteration consisting mainly of an increase of the distance between the columns of stitches was often observed.

3.2. Filament Dynamometry. When compared to the virgin reference prosthesis, explanted prostheses demonstrated a higher heterogeneity in terms of tenacity and elongation at rupture characterized by an increase of the coefficient of variation (Table 2). For the 6 explanted prostheses, the average tenacity was close to that of the virgin prosthesis except in one case where it was twice lower. Elongation at rupture dramatically decreased by a ratio of about 2.4 for long filaments and of 2.8 for short filaments in average (Table 2).
TABLE 3: Density and the percent crystallinity value of prostheses.

\begin{tabular}{lll}
\hline Protheses & $\begin{array}{l}\text { Density } \\
\left(\mathrm{g} \cdot \mathrm{cm}^{-3}\right)\end{array}$ & $\begin{array}{l}\text { Percent } \\
\text { crystallinity }(\%)\end{array}$ \\
\hline vierge & 1.4017 & 57.75 \\
A (156 mois $)$ & 1.4086 & 63.41 \\
B (168 mois $)$ & 1.4099 & 64.47 \\
C (204 mois) & 1.4098 & 64.39 \\
D (204 mois) & 1.4106 & 65.04 \\
E (240 mois $)$ & 1.4178 & 70.88 \\
F (240 mois) & 1.4167 & 69.99 \\
\hline
\end{tabular}

3.3. Density Gradient Column (DGC). The density gradient technique is an extremely accurate method for determining the density of polymers. Table 3 and Figure 9 show an increase of the density for the explanted prostheses especially for texturized yarn. These results prove that the application of physical and mechanical constraints during in vivo stay modifies the structure and the density of the polymer.

3.4. Infrared micro spectroscopy (IMS). Infrared (FTIR) spectroscopy provides a comprehensive view of chemical and conformational structures of molecules. First of all, this technique is used to analyse both virgin and explanted prosthesis in order to have an overview of the effect of chemical ageing. In this analysis, 30 fibers are extracted from various areas of each prosthesis (Figure 10).

Figure 10(a) shows no variation of the peak absorbance when regarding different areas of the virgin prosthesis (the different peak absorbances were represented by various colors). For example, there is no variation of the hydroxyl 


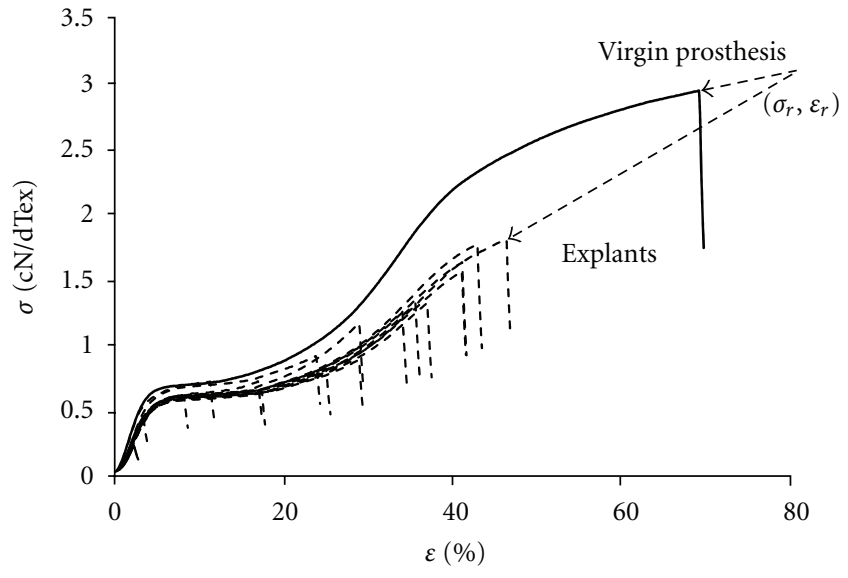

Figure 8: Classical dynamometry for various vascular prostheses.

end-groups absorbances of the virgin prosthesis (Figure $10(\mathrm{~b}))$. However, a variation of the peak absorbances of the aged sample is observed (Figure 10(c)). This behaviour may be attributed to a nonhomogeneity of the properties for the explants. Accordingly, a remarkable variation of the hydroxyl end-groups absorbances along the explanted prostheses is observed (Figure 10(d)). These tests prove that the application of chemical constraints during in vivo stay modifies the structure of the polymer and creates a nonhomogeneous degradation for the explants. SEM macroscopic examination confirms infrared microscopic examination.

Secondly, the FTIR spectroscopy was used to follow changes in chain conformation of poly(ethylene terephthalate) (PET), which occur during physical ageing (Figure 11).

The gauche $(\mathrm{G})$ or trans $(\mathrm{T})$ conformation of the ethylene glycol fragment through rotation around $\mathrm{C}-\mathrm{C}$ bond accounts for major IR spectra differences in amorphous and crystalline phases [26]. The vibration modes were extensively studied [26-29]: for example, the $1340 \mathrm{~cm}^{-1}$ band assigned to $\mathrm{CH}_{2}$ - wagging of trans ( $\mathrm{T}$ ) glycol groups, primarly found in crystalline phase, and $1370 \mathrm{~cm}^{-1}$ band for gauche $(\mathrm{G})$ form in amorphous phase. Using $1410 \mathrm{~cm}^{-1}$ band as the thickness reference provides a way to normalize spectral intensities among materials (this band has been shown to be insensitive to conformational change $[26,27])$. The mode at $1340 \mathrm{~cm}^{-1}$ (- $\mathrm{CH}_{2}-$ wagging) originates from transglycol segment, [28] making $1340 \mathrm{~cm}^{-1} / 1410 \mathrm{~cm}^{-1}$ peak ratio a good indication of the transglycol content (crystallinity). These bands were used to follow the changes in molecular structure due to ageing.

These absorption bands exhibited a greater change in intensities after ageing (Figure 8). The band at $1370 \mathrm{~cm}^{-1}$ decreases, while the band at $1340 \mathrm{~cm}^{-1}$ increases in intensity with increased transconformer (crystallinity) for all explants.

3.5. Nuclear Magnetic Resonance $\left(N M R^{H}\right)$. Many types of information can be obtained from an ${ }^{1} \mathrm{H}-\mathrm{NMR}$ spectrum, especially information regarding quantification of the number and type of chemical entities in a macromolecule. Typical NMR spectrum of PET at room temperature is shown in

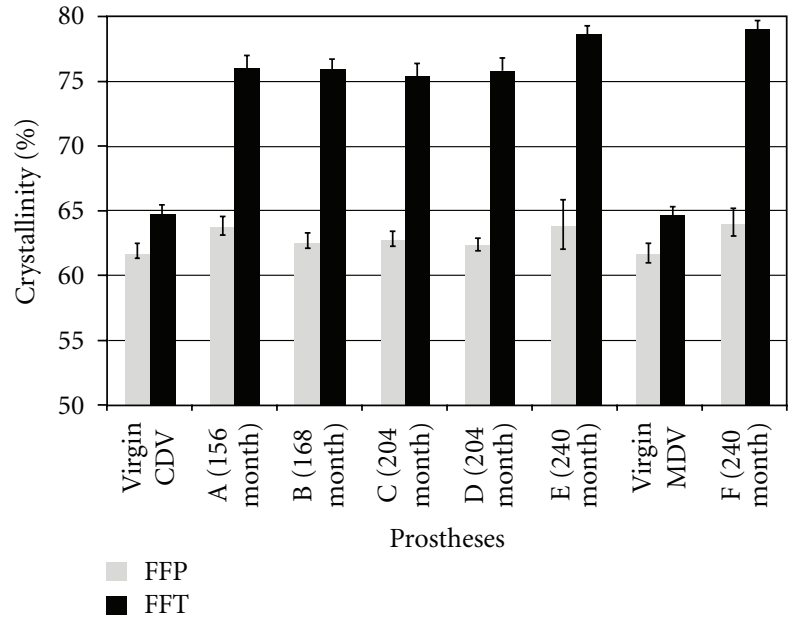

FIGURE 9: percent of crystallinity value for texturized and flat yarn.

Figure 12. Several main signals of ${ }^{1} \mathrm{H}-\mathrm{NMR}$ spectrum are detected. The chemical shifts of PET spectra were $8.13 \mathrm{ppm}$ $\left(\mathrm{H}_{1}\right)$ assigned to aromatic protons of terephthalate units and $4.69 \mathrm{ppm}\left(\mathrm{H}_{2}\right)$ assigned to methylene protons. The signals at $3.98 \mathrm{ppm}\left(\mathrm{H}_{3}\right)$ and $4.47 \mathrm{ppm}\left(\mathrm{H}_{4}\right)$ correspond to the protons in $\alpha$ - and $\beta$-position of hydroxyl end-groups, respectively $[30,31]$. The $\mathrm{H}_{6}$ and $\mathrm{H}_{5}$ signals at 3.88 and $4.5 \mathrm{ppm}$, respectively $\left(\mathrm{CH}_{2}\right.$ in $\alpha$ - and $\beta$-position of ether function), are attributed to the diethylene glycol (DEG) insertion into the PET chain, as shown by Kenwright et al. [32] Also, the ${ }^{1} \mathrm{H}$-NMR spectrum shows a very fine peak at $8.01 \mathrm{ppm}$ $\left(\mathrm{H}_{7}\right)$ corresponding to PET cyclic trimer (i.e., three repeating units), which is present in significant quantity in the PET [30]. To monitor the changes that occur in the PET polymer during in vivo stay, the signal at $8.35 \mathrm{ppm}$ corresponding to ${ }^{13} \mathrm{C}$ satellite of aromatic protons $\left(\mathrm{H}_{1}\right)$ was used to normalize all spectra.

3.6. Ethylene Groups. Ethylene-repeating unit comprising the PET macromolecular chain is generally the first and most important attribute of a PET polymer. To compare the ethylene groups, the signal at $4.87 \mathrm{ppm}$ corresponding to ${ }^{13} \mathrm{C}$ satellite of these groups $\left(\mathrm{H}_{2}\right)$ was used.

Figure 13 shows a slight reduction of the ethylene quantity for all explants compared to the virgin prosthesis. This reduction can be explained by the rupture of macromolecular chains in ethylene repeating unit during an in vivo stay. Many studies on the degradation of PET have been carried out, and it has been considered that the degradation of PET consists in random scission of ester linkages $[33,34]$.

The study of polymers starts by understanding the methods used to synthesize the materials. Polymer synthesis is a complex procedure and can take place in a variety of ways. Certain secondary reactions can occur during the synthesis of the PET, leading to nonconforming groups such as the formation of DEG and PET cyclic oligomer.

3.7. Diethylene Glycol. The DEG groups are formed by secondary reaction during PET synthesis (Figure 14). DEG is 


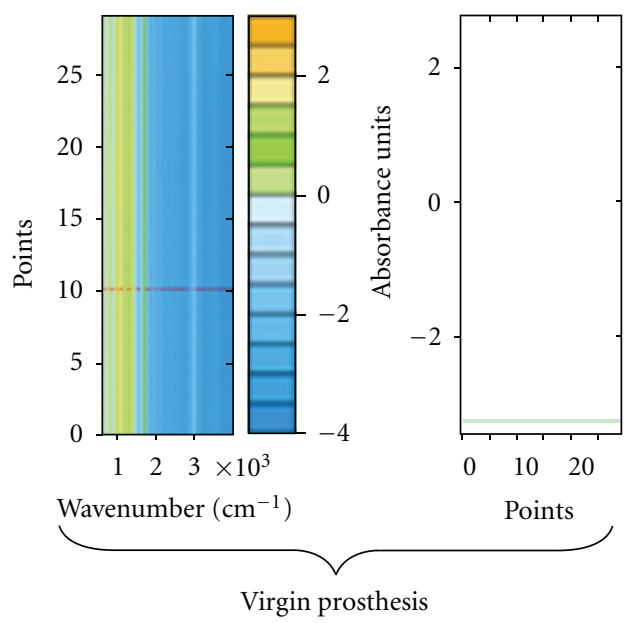

(a)

(b)

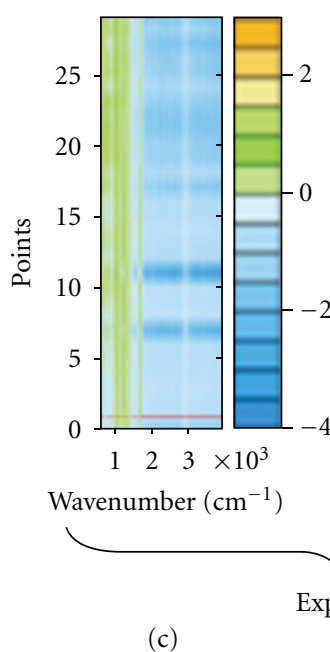

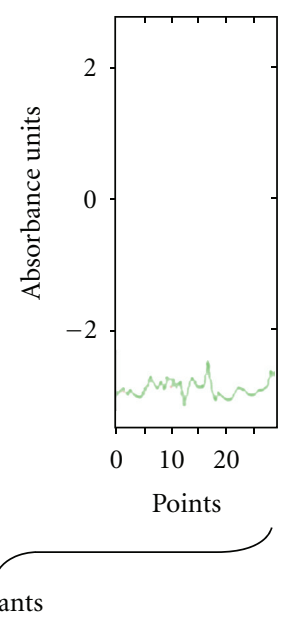

(d)

FIGURE 10: Qualitative analyses using infrared spectroscopy: $x$-axis represents the wave number and $y$-axis represents the spectrum number.

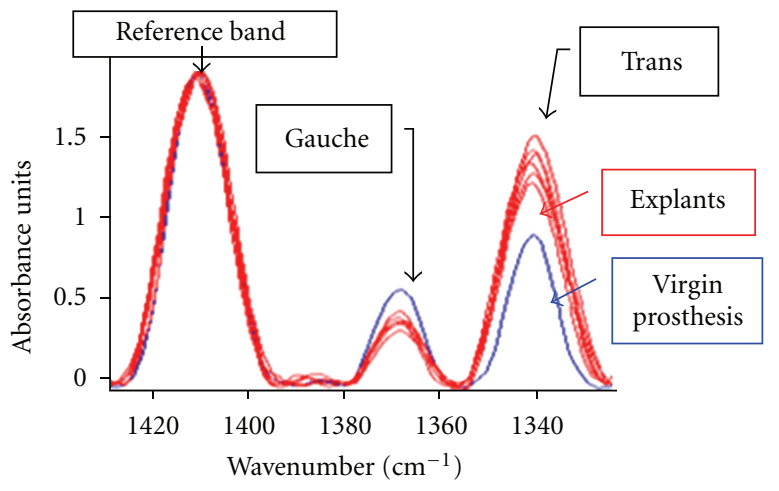

FIgURE 11: Change in absorbance of the 1340 (trans) and $1370 \mathrm{~cm}^{-1}$ (gauche) bands after implantation.

known to be a weak point in the thermal degradation of PET [35]. Lecomte and Liggat [36] confirm that there is a specific degradation of DEG units, which occurs at $100 \mathrm{~K}$ below the degradation temperature of PET. The DEG groups provide some degree of flexibility to a relatively stiff PET backbone, which slows down its crystallization [37].

3.8. Cyclic Oligomer. In the process of producing linear polymers by condensation, cyclic oligomers are inevitably formed and their formation considerably affects the macromolecular weight distribution even though the total amount formed is less than 5\% [38]. The dominant oligomeric species in PET is cyclic trimer, which accounts for more than $77 \%$ of cyclic oligomers. The PET oligomers are located essentially on the fiber surfaces [39].

Figures 15 and 16 show a remarkable reduction in the diethylene groups and PET cyclic oligomers for all explants compared to the virgin prosthesis. These results are in agreement with several authors [36-40], who said that the increase in DEG content promotes hydrolysis and oxidative degradation. Holland and Hay [32-35] proved that DEG chain ends were more prone to degradation than the rest of the PET chain, leading to the formation of dioxane and carboxylic end-groups. Therefore, after ageing, these long macromolecular chains (virgin prosthesis) have suffered severe degradation. This phenomenon is related to the formation of smaller molecules, and it may occur by random scission in DEG. Similarly, according to several authors, [36, 38], the cyclic oligomers are released early during the degradation and correspond to the first mass-loss step observed for PET.

To clarify the effect of chemical aging, the macromolecular weights of PET fibers extracted from various vascular prostheses, using NMR technique, were quantified.

3.9. Molecular Weight. ${ }^{1} \mathrm{H}-\mathrm{NMR}$ technique has been used to compare the macromolecular weight of a series of PET vascular prostheses, collected after different durations of in vivo stay.

Polymer properties are strongly dependent on the number of monomer units that comprise the macromolecular chain. Mathematically, the average number of macromolecular weight $(\mathrm{Mn})$ is given by the following formula (2):

$$
M_{n}=\sum_{i}\left(M_{i} \times \overline{\mathrm{DP}}_{\imath}\right)+M_{G}
$$

where $M$ is the molecular weight of repeating unit, $\mathrm{DP}_{i}$ is the average number of repeating unit, and $M_{G}$ is the residual molecular weight of end-groups and/or insertions.

Direct ${ }^{1} \mathrm{H}$-NMR technique is not sensitive to the carboxyl end-groups because of line broadening of the signal caused by fast chemical exchange within impurities. $\mathrm{COOH}$ endgroups are very low in comparison to $\mathrm{OH}$ end-groups, even after aging $(\mathrm{COOH}<20 \%$ and $\mathrm{OH}>80 \%$; these results are verified by chemical titration); therefore, the $\mathrm{COOH}$ groups have little influence on the evolution of $(\mathrm{Mn})$ values. Thus, the macromolecular weight will be calculated by supposing that all chains are terminated by hydroxyl groups. 

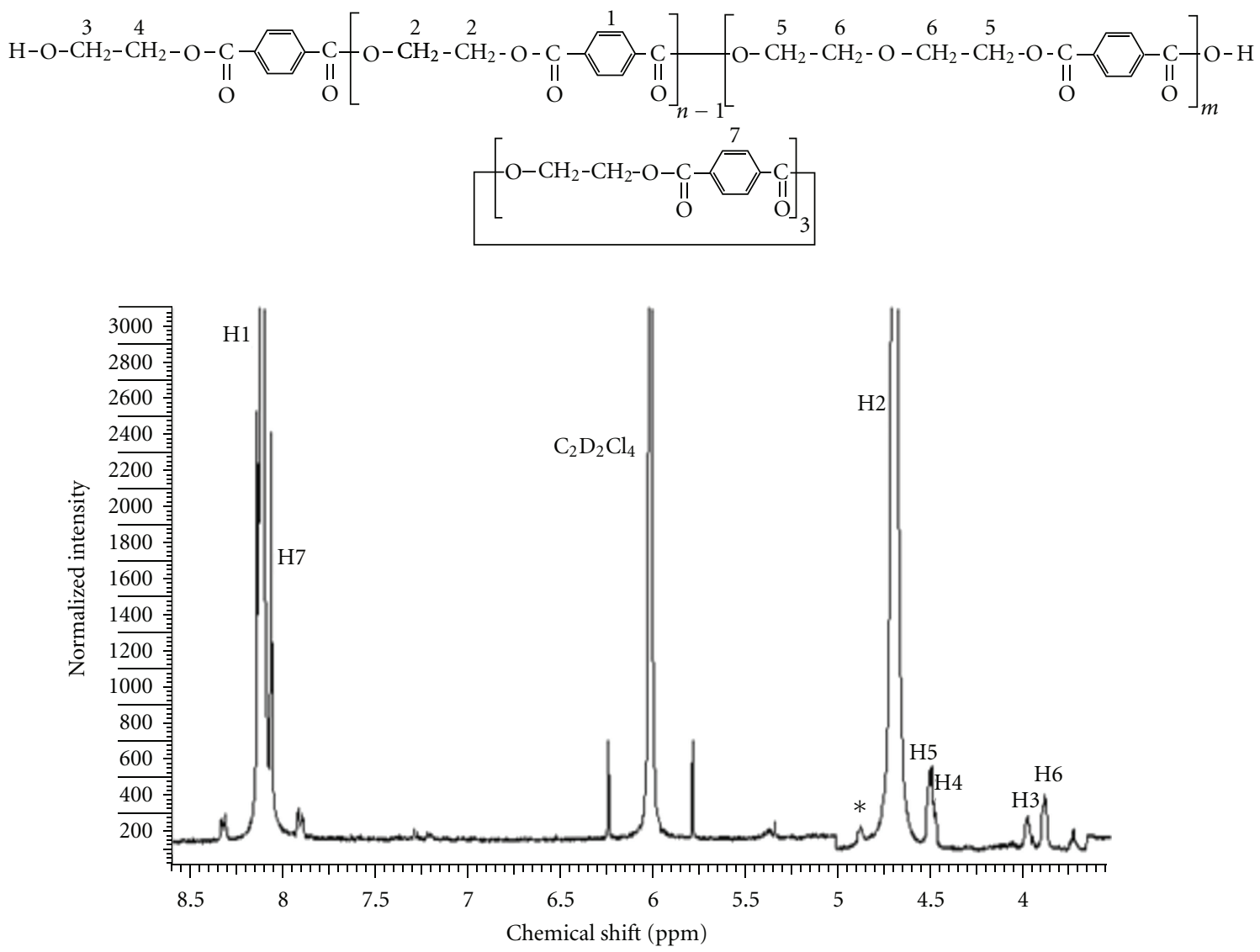

Figure 12: ${ }^{1} \mathrm{H}-\mathrm{NMR}$ spectrum of PET $\left(400 \mathrm{MHz},\left(\mathrm{CDCl}_{2}\right)_{2}\right.$, reference $\left.\left(\mathrm{CDCl}_{2}\right)_{2}, \mathrm{~d}\left(\mathrm{CHCl}_{2}\right)_{2} 6 \mathrm{ppm}\right) .{ }^{* 13} \mathrm{C}$ satellite peak.

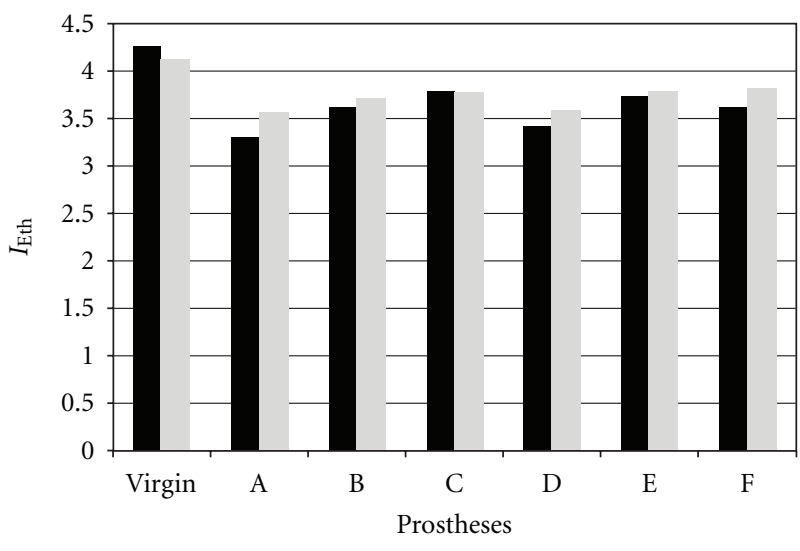

- FFT

FFP

FIGURE 13: Variation of the ethylene groups for different prostheses. $I_{\mathrm{ETH}}$ is the integral value of the ethylene group peak.

The average number macromolecular weight can be represented by the following formula (3):

$$
M_{n}=\frac{\left(\% M_{n 1}\right) \times M_{n 1}+\left(\% M_{\text {nol }}\right) \times M_{\text {nol }}}{100},
$$

where $\% M_{\mathrm{n} 1}$ is the percentage of principal polymer chain (without oligomers); $M_{\mathrm{n} 1}$ is the macromolecular weight of principal polymer chain; $\% M_{\text {nol }}$ is the percentage of oligom-

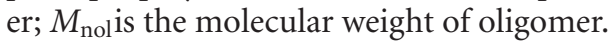

The macromolecular weight of principal PET chain $\left(M_{\mathrm{n} 1}\right)$ can be calculated by the following formula (4) (Figure 17):

$$
M_{n 1}=n \times 192+m \times 236+62 \mathrm{~g} / \mathrm{mol} .
$$

To determine $n$ and $m$, we use the integral value of ${ }^{1} \mathrm{H}$ NMR signal (integration). This signal is proportional to their proton number and this group's repeating number.

Thus, this integral value $\left(I_{i}\right)$ can be determined by the following formula (5):

$$
I_{i}=(\text { Nber } H) \times(\text { Nber } M) \times(\text { Nber } C),
$$

where Nber $H$ is the proton number in this group; Nber $M$ is the number of repetitions of this group in one macromolecular chain; Nber $C$ is the number of macromolecular chain repetitions.

Thus using the above equation, $m$ and $n$ can be calculated. The average number of diethylene repeating unit $(m)$ was calculated by using the ratio $\left(I_{6} / I_{3}\right)$ and the average number of ethylene repeating unit $(n)$ was calculated by using the ratio $\left(I_{2} / I_{3}\right)$ (Figure 17). 


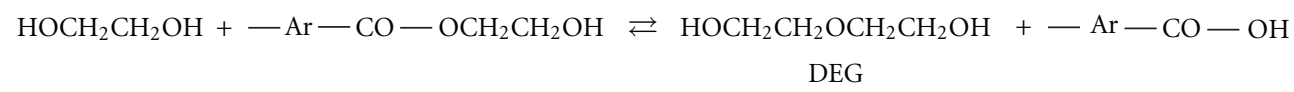

FIGURE 14: Formation of diethylene glycol (DEG).

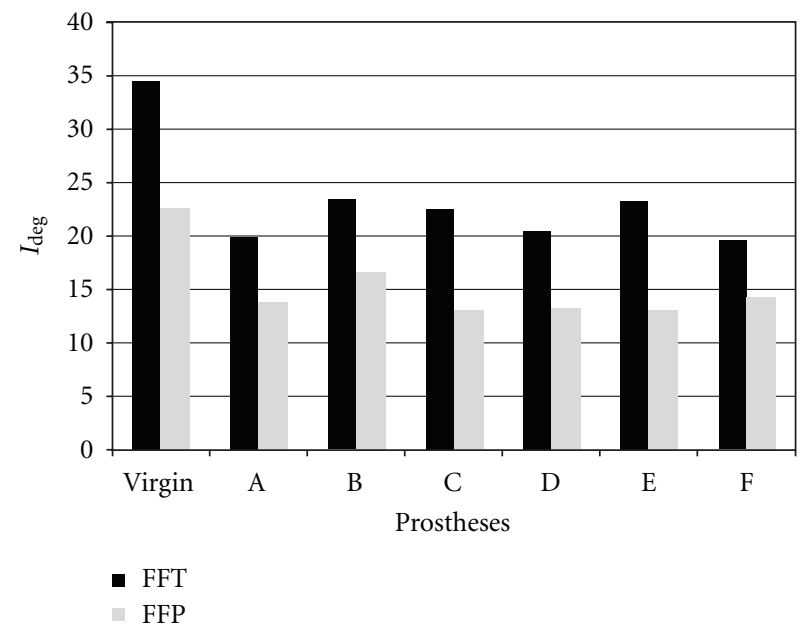

FIGURE 15: Variation of the diethylene glycol groups. $I_{\mathrm{DEG}}$ is the integral peaks values of the diethylene glycol groups.

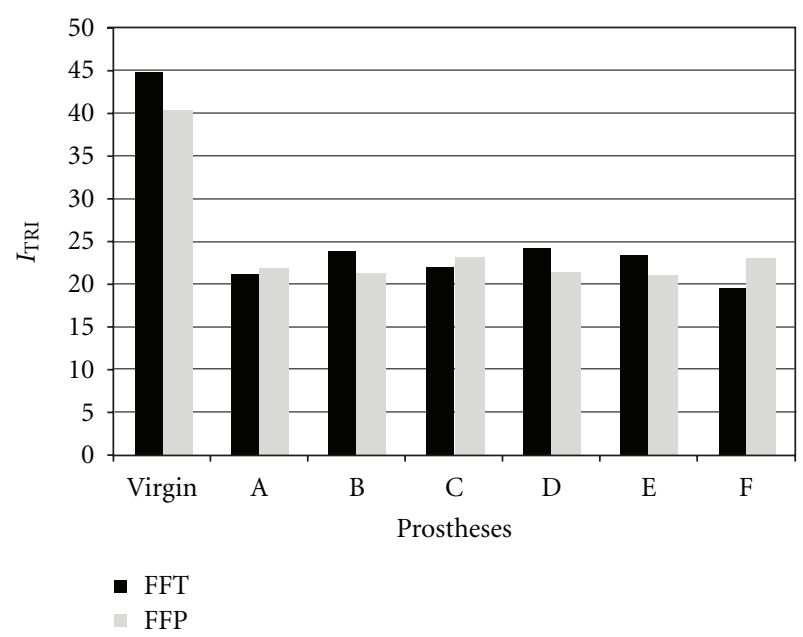

FIGURE 16: Variation of the cyclic oligomers. $I_{\text {TRI }}$ is the integral peaks values of the cyclic oligomers.

$I_{6}$ represents the integral values of the diethylene glycol and $I_{2}$ represents the integral values of the ethylene glycol. $I_{3}$ is the integral value of the $\mathrm{CH}_{2}$ in $\alpha$-position of hydroxyl end-groups $\left(\mathrm{H}_{3}\right)$. The $\mathrm{H}_{3}$ group is repeated twice by chain and it contains two protons.

The macromolecular weight of oligomer is equal to $576 \mathrm{~g} / \mathrm{mol}\left(M_{\mathrm{nol}}\right)$. The percentage of oligomer $\left(\% M_{\mathrm{nol}}\right)$ can be determined by using $\mathrm{H}_{1}$ and $\mathrm{H}_{7}$ bands:

$$
\% M_{\text {nol }}=\frac{I_{1}}{I_{1}+I_{7}}
$$

where $I_{1}$ is the integral value of the aromatic protons of principal polymer and $I_{7}$ is the integral value of the aromatic protons of oligomer.

Thus ${ }^{1} \mathrm{H}-\mathrm{NMR}$ technique has been used to compare the macromolecular weight of a series of PET vascular prostheses, collected after different durations of in vivo stay.

As a specific modification is induced by the increase of the end-groups, Figure 18 shows a strong decrease of macromolecular weight $(\mathrm{Mn})$ detected for all explants compared with the virgin prosthesis. In addition, it was observed that the textured standard yarns (FFT) are more degraded than the flat standard yarns (FFP) for different explanted prostheses (between 33.0 and 56.0\% for FFT and between 30.0 and $47.7 \%$ for FFP). These results are in good agreement with the results found in the literature [26, 41-43]. Indeed PET chemical degradation consists in a change in the properties and macromolecular weight, under the influence of one or more environmental factors such as heat, temperature, or chemicals. This degradation can be explained by a random scission of the ester linkages, which in turn leads to a decrease in the macromolecular weight of the polymer $[26,34,44]$.

While the results showed that the macromolecular weight values $(\mathrm{Mn})$ are significantly influenced by aging following implantation, the impact of the duration of in vivo stay on the chemical degradation was difficult to evaluate. We noticed that these $(\mathrm{Mn})$ of the fibers extracted from vascular prostheses are not directly correlated to the duration of in vivo stay (e.g., the prosthesis (E: 156 months) is more degraded than the prosthesis (A: 204 months)). Therefore, the degradation level does not depend on the time of in vivo stay or the location of the implant (Table 1). These results are in good agreement with the literature [45].

Moreover, degraded chains (explants) with low molecular weight exhibit a remarkable reduction in DEG and PET oligomers.

\section{Discussion}

Ruptures of polyester textile prostheses have been rarely reported in the literature. In a previous study $[3,15,24]$ as a part of a European collaborative program, we collected 20 cases of ruptures occurring on two similar prostheses constructed by the same manufacturer. We demonstrated that these ruptures were not randomly distributed on the textile structure of these warp-knitted prostheses but that they occurred on two well-defined areas: the remeshing line and the guide line.

The goal of the present study was to determine if these areas of weakness could have been predicted by in vitro investigations of virgin prostheses associating mechanical and chemical analyses. The prostheses that demonstrated ruptures in our series were Cooley Double Velour and Microvel Double Velour of the first generation incorporating 

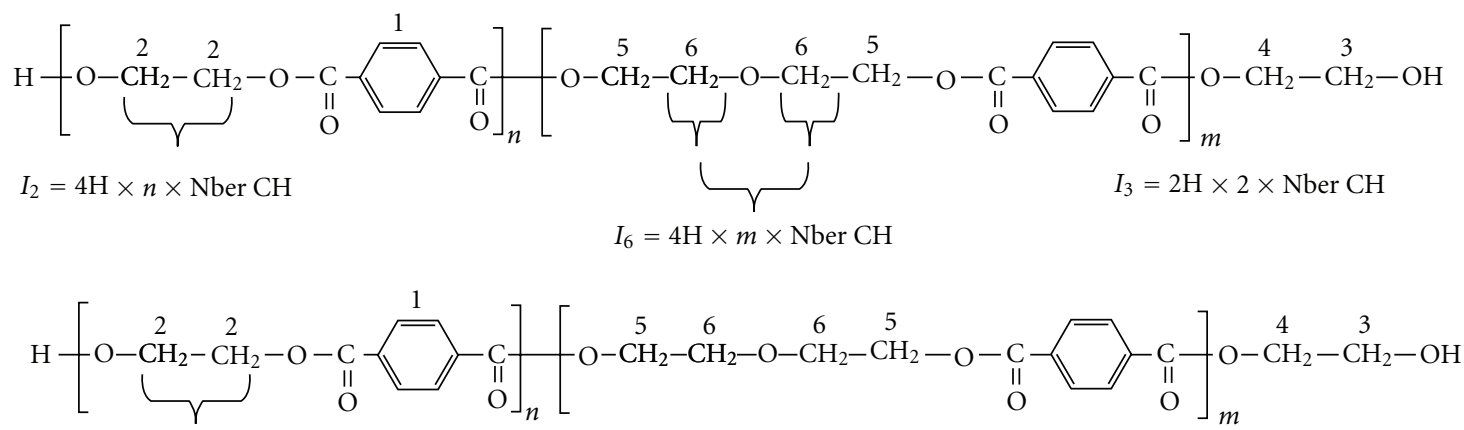

FIGURE 17: PET group intensities in macromolecular chain with hydroxyl termination.

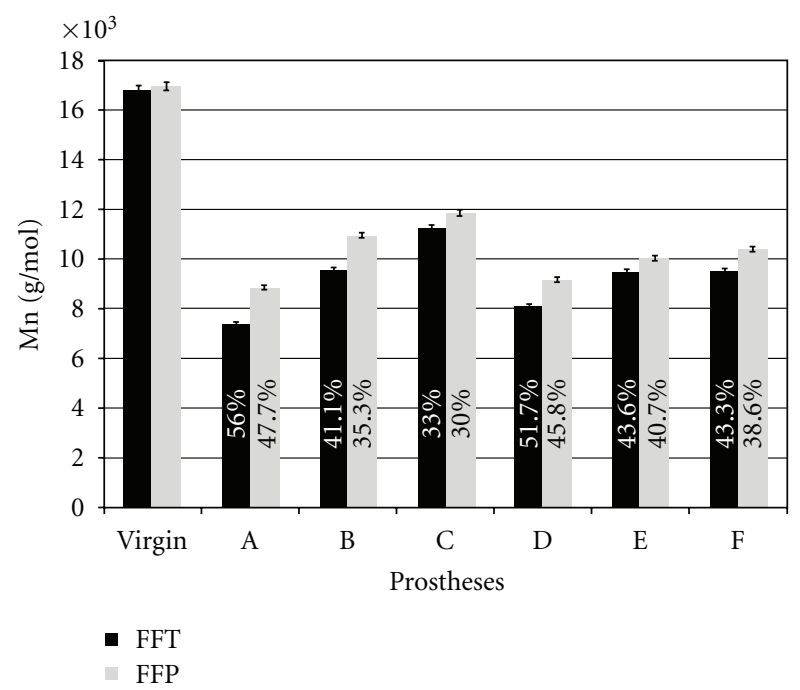

FIGURE 18: Macromolecular weight for various vascular prostheses using $1 \mathrm{H}-\mathrm{NMR}$ method.

texturized trilobate filaments. Unfortunately, the virgin prostheses corresponding to the first generation were no longer available so we used virgin prostheses from the second generation. The second-generation prostheses use cylindrical texturized filaments instead of the trilobate ones. Filament dynamometry highlighted modifications of the mechanical behavior of monofilaments after the manufacturing of the prosthesis. The resistance of a yarn is equal to the resistance of each filament multiplied by the number of filaments. The study of the mechanical behavior of the filaments taken from yarns extracted from the different areas of the prostheses highlighted two phenomena. First, we observed heterogeneity of the mechanical behavior of the filaments inside a same yarn, with this heterogeneity being characterized by major differences in terms of resistance and breaking extension. Secondly, we showed differences in mechanical behavior of the filaments according to the area from where the yarns were extracted. We believe that this heterogeneity of mechanical behavior may lead to the rupture observed in the textile structure. In these conditions of heterogeneous behavior of the filaments inside a yarn, the resistance of a yarn depends greatly on the resistance of the weakest filament. Consequently, such a yarn will be exposed to a gradual rupture of the filaments, which may generate longitudinal tears in the prosthesis as described on the explanted prostheses in human.

Both prostheses were constructed with a short yarn and a long texturized yarn. The texturization of a long yarn deeply modified the elongation properties of the filaments. Consequently, it is logical to find significant difference of mechanical behavior between short and long yarn inside the same column of stitches.

During the manufacturing process, the polyester filaments and yarns can be degraded by texturization. This is obtained by thermofixation after the application of longitudinal or transverse stresses and of torsion. It will generate irregularities of the structure and the geometry of the filaments. After knitting, the prostheses are compacted in order to decrease its porosity by a thermal and/or chemical swelling of the polyester filaments. This treatment can also modify the molecular arrangement, and the orientation or the crystallinity of the polymer, affecting its mechanical properties. Crimping can also modify the filaments since it is carried out by thermofixation. The application of mechanical and thermal constraints can also modify the structure of the polymer and create the deformations of the filaments as observed by scanning electron microscopy. Finally, the prosthesis is cleaned with chemical reactants that may modify the surface chemistry of the polyester filaments. The prosthesis can also be degraded at the time of its implantation. All these deteriorations of the textile structure occurring before or during the implantation of the prosthesis could promote an accelerated in vivo biodegradation of particular types of prostheses. After the implantation, the pulsatile arterial stress and the enzymatic environment of the tissular host response may accelerate the polymer degradation.

Table 3 shows an increase in crystallinity percentage for all explants compared to virgin prosthesis. This increase can be explained by the rupture of macromolecular chains in amorphous areas during an in vivo stay (Figure 19). Thus, these short-chains are considerably more mobile than longchains which cause an increase in crystallinity percentage.

Infrared microscopic examination confirms filament dynamometry results. Similarly, the homogeneity properties of the filaments taken from the virgin prosthesis and the 


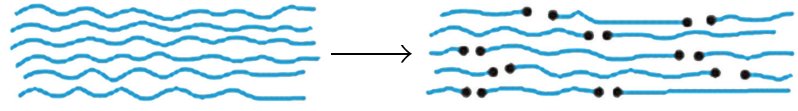

Macromolecular chains
- End-groups

FIGURE 19: Chain scission in macromolecules [48].

heterogeneity of the filaments taken from the explanted prosthesis were highlighted (Figure 10).

Infrared (FTIR) spectroscopy can be a very powerful tool for studying chemical structure in bulk materials as well as providing molecular conformation details that are inaccessible to most analytical methods. Thus, we used the FTIR technique to measure the crystalline and amorphous content in PET, using absorption bands at $1340 \mathrm{~cm}^{-1}$ and $1370 \mathrm{~cm}^{-1}$, respectively, with the band at $1410 \mathrm{~cm}^{-1}$ as an internal standard. It has been shown that there is an increase in the population of transethylene glycol conformation (crystalline phase) at the expense of the gauche (amorphous phase) after physical ageing, that is, one structural alteration that occurs on physical ageing is the change from gauche to transconformations of the ethylene units in PET.

${ }^{1} \mathrm{H}$ NMR method provides a convenient mean to quantify the effect of chemical ageing for various explants. Examination of a series of PET vascular prostheses showed significant chemical differences between the virgin prostheses and the explants collected after ageing, especially for diethylene glycol (DEG) groups. Ageing was investigated in terms of chemical scission of ester and ether linkages caused by hydrolytic and oxidative reaction during in vivo stay (Figure 19). Therefore, after ageing, these long macromolecular chains (virgin prosthesis) have suffered severe degradation. This phenomenon is related to the formation of smaller molecules and it may proceed by random scission in DEG. Similarly, according to several authors $[36,38]$, the cyclic oligomers are released early during the degradation and correspond to the first mass-loss step observed for PET.

All of these studies in the literature coupled with our results (formation of small crystallites in amorphous areas) allow establishing hypotheses about the structural evolution of the polymer after ageing. On the one hand, we showed that the explants had a higher degree of crystallinity than virgin prostheses, and on the other hand, there was a development of small crystallites in the amorphous areas for the explants. This crystallization would begin to occur by the rupture of macromolecular chains mainly at the amorphous areas. So, small more mobile chains appear, which would favor the crystallization in the amorphous areas after ageing. However, these small crystallites are not perfectly oriented along the fiber axis (Figure 20).

Although, we distinguished a remarkable reduction of the average number of $(\mathrm{Mn})$, it could be due to the fact that just small parts of some chains come off dramatically reducing number average molecular weight, but probably not weighted average molecular weight. Consequently, the ruptures of macromolecular chain do not cause a damage

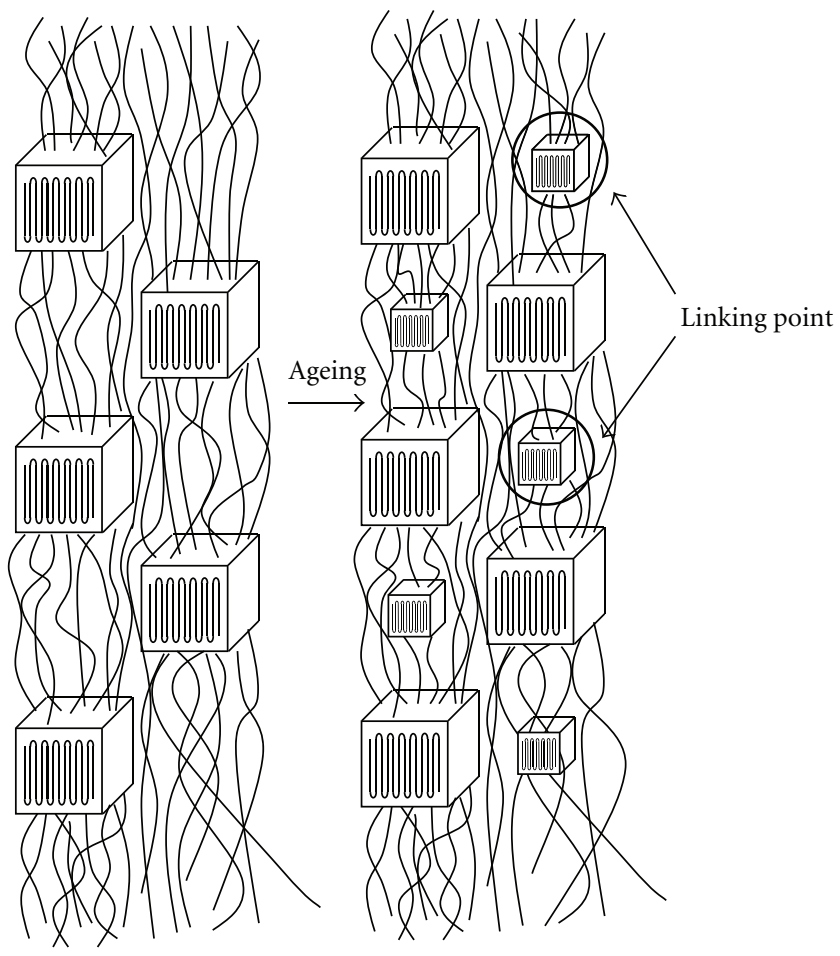

FIGURE 20: appearance of crystallites in the amorphous areas: the break of diethylene glycol groups existing in the amorphous areas may promote the crystallization process and thus the transformation of CIS conformers (present in the amorphous zones) in TRANS (present in the crystalline regions).

or a dramatically degradation of the vascular prostheses. But the classical dynamometry test (Figure 8, Table 2) shows a strong decrease of the mechanical properties (the breaking extension $\left(\varepsilon_{r}\right)$ for all explants compared to the virgin prosthesis.

These failures are related to lesions during the implantation and the chemical degradation of materials in vivo. According to several authors [46, 47], the mechanical properties, especially the breaking stress $\left(\sigma_{r}\right)$ are not influenced by the $(\mathrm{Mn})$ values until they decrease to a critical value. Beyond this critical point (i.e., when the $(\mathrm{Mn})$ values decrease under the value of $\mathrm{Mn}_{c r}$ (Figure 21)), the mechanical properties, especially the breaking stress, are greatly weakened. The chemical ageing may induce serious degradation of the breaking stress and therefore can justify the decrease of the $(\mathrm{Mn})$ values found for the explanted prostheses and consequently the weighted average molecular weight.

In the future, we hope to find a correlation between $\mathrm{Mn}$ and the length of chain and therefore obtain a critical value of $(\mathrm{Mn})$ to monitor the aging behavior. Also, it is relevant to determine polydispersity index to verify the found results and the macromolecular chain repartition.

\section{Conclusions}

The ruptures observed on explanted knitted vascular polyester prostheses in humans occurred on areas that can be 


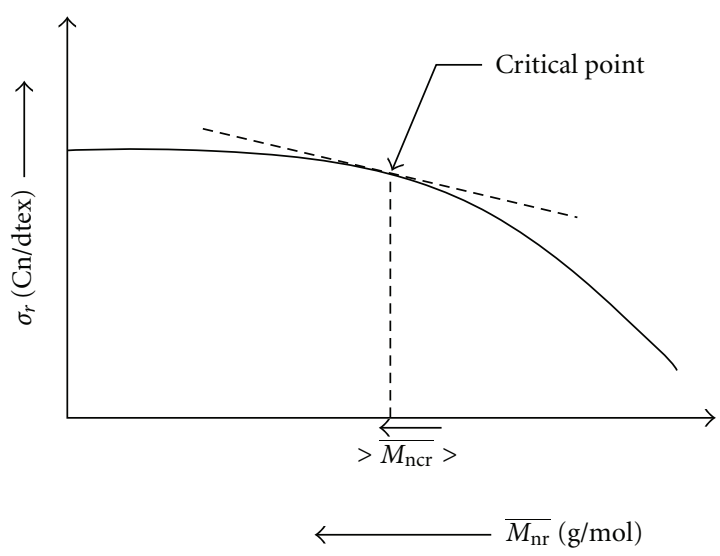

FIgURE 21: Theoretical relationship between macromolecular weight and breaking stress [46].

qualified as areas of weakness. These areas of weakness seem to be related to the manufacturing process, the implantation, and the human metabolism, which may induce physical and chemical modifications of the polyester yarns. These alterations may be considered as a premature ageing of the polyester before its implantation.

So, this study confirmed the high level of polymer degradation in prostheses by the presence of structural anomalies. These anomalies are weaknesses that initiate the degradation and the ageing process.

New generations of vascular fabrics, who are also prone to rupture, should require a more controlled manufacturing process and the use of a PET specifically synthetized for medical applications. The synthetized PET should have less structural anomalies in order to be less prone to in vivo oxidation.

\section{Acknowledgments}

The authors' work on the degradation of the prostheses was carried out at the Laboratory of Physics and Textile Mechanics of the Ecole Nationale Supérieure des Industries Textiles of Mulhouse in collaboration with the Laboratoire de Chimie Organique et Bio-organique, of the École Nationale Supérieure de Chimie de Mulhouse of Mulhouse. The authors' would like to thank the the Lucien Dreyfuss Foundation, the Regional Council of Alsace, and the Entente Franco-allemande Foundation for their financial help. They would also like to thank the Institute of Biomechanics of Hamburg.

\section{References}

[1] H. B. Voorhees, A. Jorretski, and A. H. Blakemore, "The use of tubes construted from vinyon "N" in cloth bridging arterial defects: a preliminary report," Annals of Surgery, vol. 135, no. 2, pp. 332-336, 1952.

[2] N. Chakfé, F. Dieval, G. Riepe et al., "Influence of the textile structure on the degradation of explanted aortic endoprostheses," European Journal of Vascular and Endovascular Surgery, vol. 27, no. 1, pp. 33-41, 2004.
[3] N. Chakfé, G. Riepe, F. Dieval et al., "Longitudinal ruptures of polyester knitted vascular prostheses," Journal of Vascular Surgery, vol. 33, no. 5, pp. 1015-1021, 2001.

[4] N. Chakfé, F. Dieval, F. Thaveau et al., "Aneurysm of expanded polyetrafluoroethylene vascular graft: an ultrastructural analysis," European Journal of Vascular and Endovascular Surgery, vol. 25, pp. 360-366, 2003.

[5] G. E. Sweet and J. P. Bell, "Chemical degradative stress cracking of poly (ethylene terephthalate) fibers," Journal of Polymer Science, vol. 16, no. 11, pp. 2057-2077, 1978.

[6] J. G. Sladen, A. N. Gerein, and R. T. Miyagishima, "Late rupture of prosthetic aortic grafts. Presentation and management," American Journal of Surgery, vol. 153, no. 5, pp. 453458, 1987.

[7] M. Batt, M. King, and R. Guidoin, "Mechanical fatigue in a polyester arterial prosthesis," Presse Medicale, vol. 13, no. 33, pp. 1997-2000, 1984.

[8] A. Conix, "On the molecular-weight determination of poly(ethylene terephthalate)," Macromolecular Chemistry and Physics, vol. 26, no. 1, pp. 226-235, 1958.

[9] H. A. Pohl, "Determination of carboxyl end groups in a polyester, polyethylene terephthalate," Analytical Chemistry, vol. 26, no. 10, pp. 1614-1616, 1954.

[10] M. J. Maurice and F. Huizinga, "The determination of carboxyl groups in polyethylene terephthalate," Analytica Chimica Acta, vol. 22, pp. 363-368, 1960.

[11] R. Guidoin and N. Chakfé, "Aneurysmal deterioration of arterial substitutes," in Current Therapy in Vascular Surgery, C. B. Ernst, J. C. Stanley, and B. C. Decker, Eds., pp. 324-328, BC Decker, Toronto, Canada, 1990.

[12] K. Berger and L. R. Sauvage, "Late fiber deterioration in Dacron (B) arterial grafts," Annals of Surgery, vol. 193, no. 4, pp. 477-491, 1981.

[13] D. B. Nunn, M. H. Freeman, and P. C. Hudgins, "Postoperative alterations in size of dacron aortic grafts. An ultrasonic evaluation," Annals of Surgery, vol. 189, no. 6, pp. 741-745, 1979.

[14] B. Pourdeyhimi and D. Wagner, "On the correlation between the failure of vascular grafts and their structural and material properties: a critical analysis," Journal of Biomedical Materials Research, vol. 20, no. 3, pp. 375-409, 1986.

[15] F. Diéval, D. Mathieu, and B. Durand, "Influence of textile structure on longitudinal ruptures' localization of the vascular prostheses," Textile Research Journal, vol. 78, no. 5, pp. 427438, 2008.

[16] R. M. Blumenberg and M. L. Gelfand, "Failure of knitted Dacron as an arterial prosthesis," Surgery, vol. 81, no. 5, pp. 493-496, 1977.

[17] A. Trippestad, "Late rupture of knitted Dacron double velour arterial prostheses," Acta Chirurgica Scandinavica, vol. 151, no. 4, pp. 391-395, 1985.

[18] P. A. Cooke, P. A. Nobis, and R. J. Stoney, "Dacron aortic graft failure," Archives of Surgery, vol. 108, no. 1, pp. 101-103, 1974.

[19] J. J. Yashar, M. H. Richman, J. Dyckman et al., "Failure of Dacron prosthesis cause by structural defect," Surgery, vol. 84, no. 5, pp. 659-663, 1978.

[20] R. C. Nucho and W. A. Gryboski, "Aneurysms of a double velour aortic graft," Archives of Surgery, vol. 119, no. 10, pp. 1182-1184, 1984.

[21] M. T. F. D. Vrancken Peeters, A. Voorwinde, A. J. C. MacKaay, and R. M. J. M. Butzelaar, "Late rupture of femoropopliteal Dacron grafts: a rare complication," European Journal of Vascular and Endovascular Surgery, vol. 11, no. 2, pp. 243-246, 1996. 
[22] S. E. Wilson, R. Krug, G. Mueller, and L. Wilson, "Late disruption of Dacron aortic grafts," Annals of Vascular Surgery, vol. 11, no. 4, pp. 383-386, 1997.

[23] G. Riepe, J. Loos, H. Imig et al., "Long-term in vivo alterations of polyester vascular grafts in humans," European Journal of Vascular and Endovascular Surgery, vol. 13, no. 6, pp. 540-548, 1997.

[24] F. Dieval, N. Chakfé, L. Wang et al., "Mechanisms of rupture of knitted polyester vascular prostheses: an in vitro analysis of virgin prostheses," European Journal of Vascular and Endovascular Surgery, vol. 26, no. 4, pp. 429-436, 2003.

[25] E. W. Fischer, H. Goddar, and G. F. Schmidt, "Détermination du degré de cristallinité des polymères tirés par des mesures de densité," Journal of Polymer Science Part B, vol. 7, no. 1, pp. 37-45, 1969.

[26] C. Sammon, J. Yarwood, and N. Everall, "FT-IR study of the effect of hydrolytic degradation on the structure of thin PET films," Polymer Degradation and Stability, vol. 67, no. 1, pp. $149-158,2000$.

[27] A. K. Jain and V. B. Gupta, "Infrared spectroscopic study of molecular orientation in heat-set poly (ethylene terephthalate) yarn using attenuated total reflection technique," Journal of Applied Polymer Science, vol. 41, no. 11-12, pp. 2931-2939, 1990.

[28] J. R. Atkinson, F. Biddlestone, and J. N. Hay, "An investigation of glass formation and physical ageing in poly(ethylene terephthalate) by FT-IR spectroscopy," Polymer, vol. 41, no. 18, pp. 6965-6968, 2000.

[29] Z. Zhu and M. J. Kelley, "IR spectroscopic investigation of the effect of deep UV irradiation on PET films," Polymer, vol. 46, no. 20, pp. 8883-8891, 2005.

[30] M. Dannoux, P. Cassagnau, and A. Michel, "Synthesis of oligoester $\alpha, \omega$-diols by alcoholysis of PET through the reactive extrusion process," Canadian Journal of Chemical Engineering, vol. 80, no. 6, pp. 1075-1082, 2002.

[31] W. Tang, N. S. Murthy, F. Mares, M. E. McDonnell, and S. A. Curran, "Poly(ethylene terephthalate)-poly(caprolactone) block copolymer. I. Synthesis, reactive extrusion, and fiber morphology," Journal of Applied Polymer Science, vol. 74, no. 7, pp. 1858-1867, 1999.

[32] A. M. Kenwright, S. K. Peace, R. W. Richards, A. Bunn, and W. A. MacDonald, "End group modification in poly(ethylene terephthalate)," Polymer, vol. 40, no. 8, pp. 2035-2040, 1999.

[33] B. J. Holland and J. N. Hay, "Analysis of comonomer content and cyclic oligomers of poly(ethylene terephthalate)," Polymer, vol. 43, no. 6, pp. 1797-1804, 2002.

[34] S. Tate and H. Narusawa, "Thermal degradation and melt viscosity of ultra-high-molecular-weight poly(ethylene terephthalate)," Polymer, vol. 37, no. 9, pp. 1583-1587, 1996.

[35] B. J. Holland and J. N. Hay, "The thermal degradation of PET and analogous polyesters measured by thermal analysisFourier transform infrared spectroscopy," Polymer, vol. 43, no. 6, pp. 1835-1847, 2002.

[36] H. A. Lecomte and J. J. Liggat, "Degradation mechanism of diethylene glycol units in a terephthalate polymer," Polymer Degradation and Stability, vol. 91, no. 4, pp. 681-689, 2006.

[37] Z. Yin, C. Koulic, C. Pagnoulle, and R. Jérôme, "Controlled synthesis of anthracene-labeled $\omega$-amine polystyrene to be used as a probe for interfacial reaction with mutually reactive PMMA," Macromolecular Chemistry and Physics, vol. 203, no. 14, pp. 2021-2028, 2002.

[38] S. C. Jun, H. Y. Ji, H. J. Won, W. K. Suk, H. Wan, and I. Y. Dong, "Cyclization routes for formation of cyclic oligomers in poly(ethylene terephthalate)," Macromolecular Chemistry and Physics, vol. 202, no. 7, pp. 998-1003, 2001.

[39] S. P. Rwei and S. K. Ni, "Formation, characterization, and prevention of dust generated during fiber or fabric processing of PET materials," Textile Research Journal, vol. 74, no. 7, pp. 581586, 2004.

[40] S. S. Hosseini, S. Taheri, A. Zadhoush, and A. MehrabaniZeinabad, "Hydrolytic degradation of poly(ethylene terephthalate)," Journal of Applied Polymer Science, vol. 103, no. 4, pp. 2304-2309, 2007.

[41] S. Al-AbdulRazzak, E. A. Lofgren, and S. A. Jabarin, "End$\backslash$ linebreak group determination in poly(ethylene terephthalate) by infrared spectroscopy," Polymer International, vol. 51, no. 2, pp. 174-182, 2002.

[42] Y. Ma, U. S. Agarwal, J. A. J. M. Vekemans, and D. J. Sikkema, "NMR based determination of minute acid functionality: endgroups in Pet," Polymer, vol. 44, no. 16, pp. 4429-4434, 2003.

[43] A. O'Neill and A. Cavaco-Paulo, "Monitoring biotransformations in polyesters," Biocatalysis and Biotransformation, vol. 22, no. 5-6, pp. 353-356, 2004.

[44] K. H. Lee, C. Y. Won, C. C. Chu, and I. Gitsov, "Hydrolysis of biodegradable polymers by superoxide ions," Journal of Polymer Science, Part A, vol. 37, no. 18, pp. 3558-3567, 1999.

[45] J. M. Maarek and R. Guidoin, "Molecular weight characterization of virgin and explanted polyester arterial prostheses," Journal of Biomedical Materials Research, vol. 18, no. 8, pp. 881-894, 1984.

[46] K. Jordens, G. L. Wilkes, J. Janzen, D. C. Rohlfing, and M. B. Welch, "The influence of molecular weight and thermal history on the thermal, rheological, and mechanical properties of metallocene-catalyzed linear polyethylenes," Polymer, vol. 41, no. 19, pp. 7175-7192, 2000.

[47] M. P. Grosvenor and J. N. Staniforth, "The effect of molecular weight on the rheological and tensile properties of poly $(\varepsilon-$ caprolactone)," International Journal of Pharmaceutics, vol. 135, no. 1-2, pp. 103-109, 1996.

[48] E. Richaud and J. Verdu, Vieillissement chimique des polymères. Mécanismes de degradation. Techniques de l'ingenieur, AM3151, January 201. 

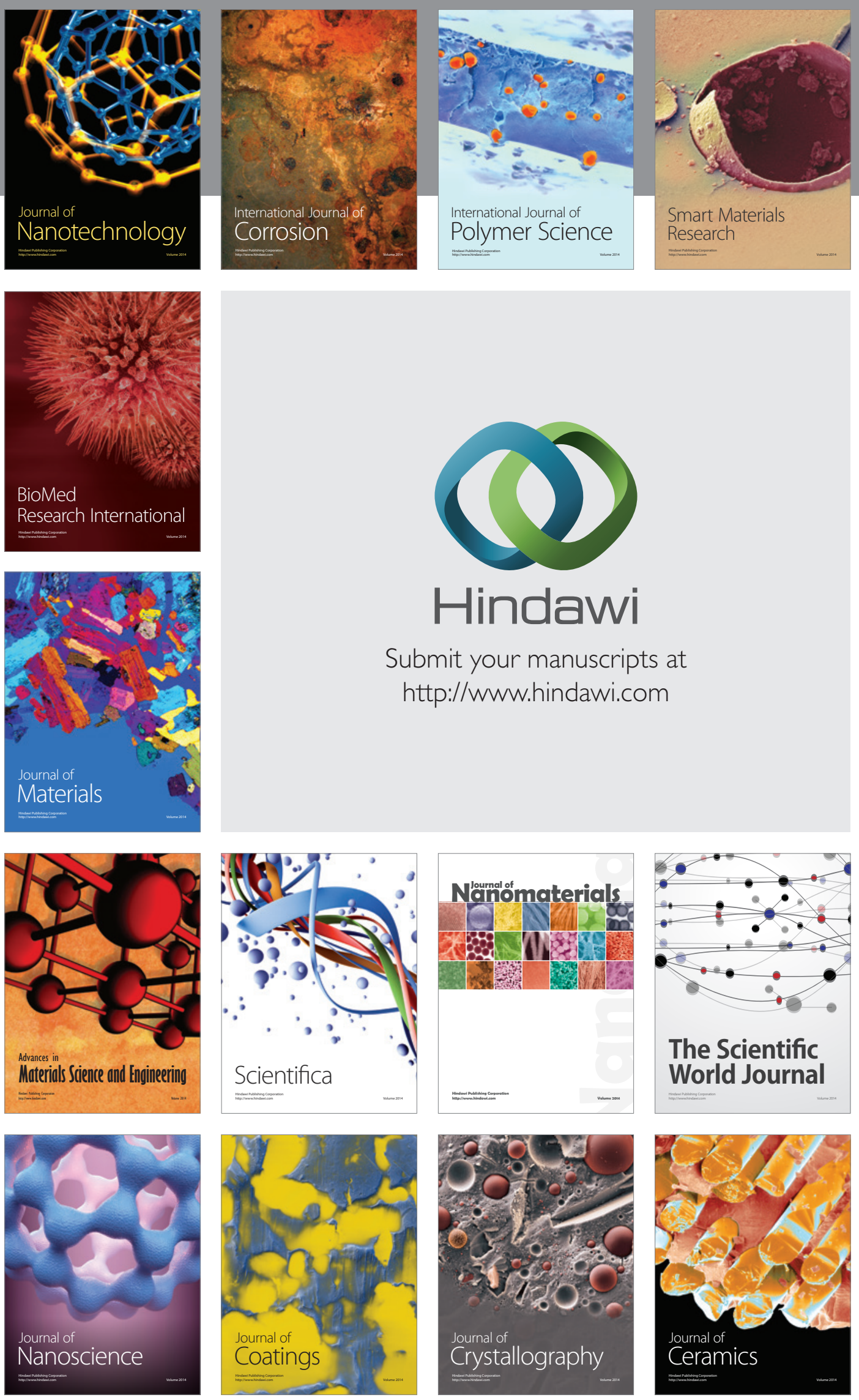

The Scientific World Journal

Submit your manuscripts at

http://www.hindawi.com

\section{World Journal}

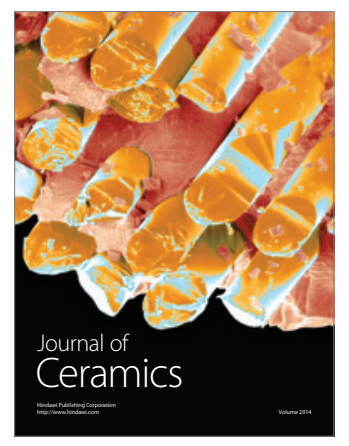

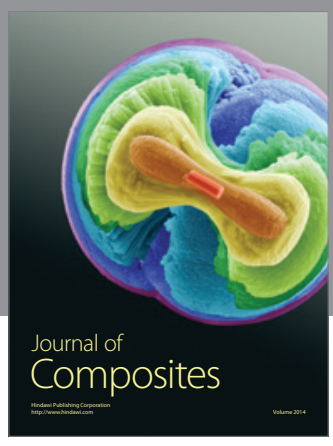
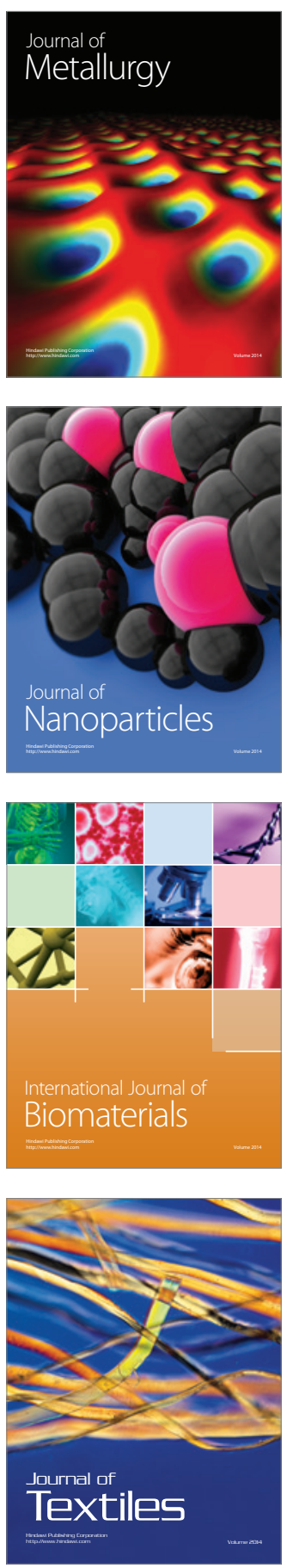